ERstad, B. L. \& Cotugno, C. L. (1995) Management of alcohol withdrawal. American Joumal of Health-System Pharmacy, 82, 697-709.

Hession M. A., Verma, S. \& MOHAN BhaKta, K. G. (1979) Dependence on chlormethlazole and effects of its withdrawal. Lancet, $t$, 953-954.

KAIM, S. C., KLETT, C. J. \& ROTHFELD, B. (1969) Treatment of the acute alcohol withdrawal state: a comparison of four drugs. American Joumal of Psychiatry, 125, 1640-1646.

LAPIERRE, Y. D., BULMER, D. R., OYEWUM, M. L., et al (1983) Comparison of chlormethiazole (Heminevrin) and chlordiazepoxdde (Lbrium) in the treatment of acute alcohol withdrawal. Neuropsychobiology, 10, 127-130.

MAJUMDAR, S. K. (1990) Chlormethiazole: current status in the treatment of the acute ethanol withdrawal syndrome. Drug and Drug Dependence, 27, 201-207.

MCGRATH, S. D. (1975) A controlled trial of chlormethiazole and chlordiazepoxdde in the treatment of the acute withdrawal phase of alcoholism. British Joumal of Addiction, 70, 81-90.

MCINNES, G. T. (1987) Chlormethiazole and alcohol: a lethal cocktail. British Medical Journal, 284, 592.

Robinson, B. J., Robinson, G. M. Manng, T. J. B. et al (1989) Is clonidine useful in the treatment of alcohol withdrawal? Alcoholism: Clinical and Experimental Research, 18, 95-98.

Denise Duncan, Senior Drug Information Pharmacist: *David Taylor, Chief Pharmacist. The Maudsley Hospital, Denmark Hill, London SE5 8AZ

*Correspondence

\title{
Treatment options for rapid-cycling bipolar affective disorder
}

\author{
David Taylor and Denise Duncan
}

Rapid cycling (RC) occurs in up to $20 \%$ of patients with bipolar affective disorder and is particularly common in women. It is generally defined as a condition where four or more episodes of (hypo-) mania or depression occur in any year. Frequently, patients with $\mathrm{RC}$ switch rapidly between episodes without passing through a euthymic stage. RC is notoriously difficult to treat and the refractoriness of the condition has led to a number of drugs and combinations being put forward as potential therapeutic interventions. This article reviews current treatments and suggests a treatment strategy based on avallable evidence of efficacy and tolerability.

\section{Lithium}

Lithium is the mainstay of the treatment of bipolar affective disorder as a whole, where it is effective in around two-thirds of patients (Prien \& Gelenberg, 1989). Many of those that do not respond to lithium are rapid-cyclers; indeed lithium's relatively poor efficacy in RC has long been known (Dunner \& Fleve, 1974) and average treatment failure rates in RC may be as high as around 80\% (Calabrese \& Woyshville, 1995). Nevertheless, lithium's safety and tolerability are well-established and so it remains a drug of first choice, even in RC. Its observed poor efficacy in some patients, however, has forced the development of other therapies.

\section{Carbamazepine}

Carbamazepine is now widely used in a variety of mood disorders and is probably at least as effective as lithium in most aspects of bipolar affective disorder (e.g. Shaw, 1988; Small et al, 1991, among many others). The efficacy of carbamazepine in RC is well-established. Joyce (1988), in an open trial of six months' duration. found that a small proportion (2/12) of lithium non-responders with RC showed a useful response to carbamazepine alone and several more $(5 / 12)$ responded to carbamazepine plus lithium. Calabrese \& Woyshville (1995) abstracted data on 
rapid-cyclers from broader studies and found that carbamazepine appeared to be partly effective in the treatment of mania (52\% response) and in prophylaxis (58\% response).

Based on this limited evidence, and the drug's long history of safety, carbamazepine should also be considered a drug of first choice in RC.

\section{Valproate}

Like carbamazepine, valproate in its various forms (sodium valproate, valproic acid, divalproex sodium) has been shown to be a very useful agent in bipolar affective disorder (Balfour \& Bryson, 1994). Data from broad-based studies appear to indicate that valproate therapy might be beneficial in $R C$ and one open study of 101 rapid cycling patients treated with valproate (Calabrese et al, 1993) lends weight to this suggestion. In this study, valproate alone and valproate with lithium and carbamazepine gave very high response rates (up to 93\%) both in acute treatment and prophylaxis. Many of the trial subjects had previously not responded to lithium or carbamazepine. Another smaller study of refractory rapid cyclers showed a similar high response rate $(6 / 6)$ to valproate either alone or in combination (McElroy et al, 1988). Thus, valproate should also be considered a drug of first choice in RC.

\section{First-line drug choice}

There are no comparative studies of lithium, carbamazepine or valproate as sole agents in RC and so all three drugs should, at present, be assumed to have equal efficacy. In addition, there is no consensus on which drug should be used first. Choice of drug must therefore depend on factors other than efficacy. These factors include individual clinical experience, specific contraindications, patient tolerability and patient preference.

\section{Combinations}

In general, polypharmacy of mood stabilisers is not advised because more adverse effects result and because the therapeutic contribution of individual drugs in a combination regimen is difficult to establish. However, some studies do indicate that combinations of any two (sometimes three) of the above drugs show additive or synergistic efficacy in bipolar affective disorder, although firm data on efficacy in RC are somewhat lacking.

Kramlinger \& Post (1988) gave carbamazepine to seven manic patients who had not responded to lithium. No improvement was seen until lithium was re-instituted, thus indicating a synergistic effect. At least one of the subjects in this study was a rapid-cycler. As already mentioned, Calabrese et al (1993) also showed that valproate was effective when added to lithium or carbamazepine, an observation confirmed in a naturalistic setting by Schaff et al (1993) who examined the effect of adding valproate to lithium or carbamazepine in 63 patients, 26 of whom were rapid cyclers. Twenty-one of the 26 rapidcycling patients responded.

\section{Thyroxine}

Several case reports from the 1980s suggested that supra-physiological doses of thyroxine were effective in RC. These early successes were the impetus for a prospective, open trial of levothyroxine in eleven patients with RC (Bauer \& Whybrow, 1990). Ten of the subjects in this study responded, despite being refractory to a range of other drugs (mainly lithium). The dose of thyroxine was slowly increased until a response occurred or until side-effects became troublesome. Effective doses ranged from $150 \mu \mathrm{g}$ to $400 \mu \mathrm{g} /$ day and gave total serum thyroid levels of nearly double the pre-treatment, euthyroid levels. Interestingly, four of the respondents underwent blind substitution of thyroxine with placebo and three relapsed. Adverse effects in all subjects appeared to be minimal. Thyroxine is evidently a worthwhile option in refractory RC.

\section{Verapamil/nimodipine}

Calcium antagonists are well known to affect mood and verapamil is occasionally used in bipolar disorder. However, verapamil's poor lipophilicity and correspondingly poor central activity have led to more lipophilic drugs being investigated. Of these, nimodipine seems to show the most promise in RC.

An early, quasi-controlled study of eight patients with lithium-refractory bipolar disorder (rapid cyclers) showed that nimodipine could prove very effective (Pazzagila et al, 1993). Indeed, two subjects showed a 'complete response' and seven of the eight improved to some extent. Further support for the use of nimodipine was provided by Goodnick (1995) who reported two cases of refractory RC where nimodipine provided virtually complete relief of symptoms.

Nimodipine also seems worthy of a trial in refractory patients. The therapeutic dose has not been established but $30-60 \mathrm{mg}$ three times a day seems to be the consensus. Adverse effects are infrequent and trivial. 


\section{Clozapine}

There are a number of case reports which appear to indicate that clozapine is effective in RC. For example, Calabrese et al (1991) found clozapine to be very effective in two patients with treatmentrefractory RC, and Suppes et al (1994) demonstrated marked efficacy in three patients with 'non psychotic' RC unresponsive to a variety of other drugs. The doses of clozapine used varied considerably but were broadly similar to those used in schizophrenia.

Clozapine may be effective in $\mathrm{RC}$ but wellcontrolled studies are needed to confirm this. In the UK, clozapine is licensed only for the treatment of treatment-refractory schizophrenia.

\section{Summary}

$\mathrm{RC}$ is a difficult condition to treat, perhaps because choice of treatment is guided by a body of research which lacks robust, definitive data. Lithium, carbamazepine or valproate should be used first as a single agent and then, if there is little or no response, in combination. Thyroxine, nimodipine and clozapine are probably effective in some patients who do not respond to standard mood stabilisers and each is worthy of a therapeutic trial in these patients.

\section{References}

BAlfour, J. A. \& BRYSON, H. M. (1994) Valproic acid - a review of its pharmacology and therapeutic potential in indications other than epilepsy. CNS Drugs, 2, 144-173.

BAUER, M. S. \& WHYBROW, P. C. (1990) Rapid cycling bipolar affecttve disorder II. Treatment of refractory rapid cycling with high dose levothyroxine: a preliminary study. Archives of General Psychiatry. 47, 435-440.

Calabrese, J. R., Meltzer, H. Y. \& MARKOVtTZ, P. J. (1991) Clozapine prophylaxis in rapid cycling bipolar disorder. Journal of Clinical Psychopharmacology. 11, 396-397.

- . Woyshvilue, M. J., KImMEL, S. E., et al (1993) Predictors of valproate response in bipolar rapid cycling. Journal of Clinical Psychopharmacology. 13, 280-283.
- \& - (1995) A medication algorithm for treatment of bipolar rapid cycling? Journal of Clinical Psychiatry. 56(suppl 3), 11-18.

DUNNER, D. L. \& FIEVE, R. R. (1974) Clinical factors in lithium carbonate prophylaxds failure. Archives of General Psychiatry, 30. 229-233.

GoODNICK, P. J. (1995) Nimodipine treatment of rapid cycling bipolar disorder. Joumal of Clinical Psychiatry, 66, 330

JOYCE, P. R. (1988) Carbamazepine in rapid cycling bipolar disorder. International Clinical Psychopharmacology, $\mathbf{3}$. 123-129.

KRAMLINGER, K. G. \& POST, R. M. (1988) Adding lithlum carbonate to carbamazepine: antimanic efficacy in treatment resistant-mania. Acta Psychiatrica Scan dinavica, 79, 378-385.

MCELROY, S. L., KECK, Jr, P.E., POPE, Jr, H. G., et al (1988) Valproate in the treatment of rapid cycling bipolar disorder. Journal of Clinical Psychopharmacology. 8. 275-279.

Pazzagila, P. J., POSt, R. M., Ketter, T. A., et al (1993) Preliminary controlled trial of nimodipine in ultra-rapid cycling affective dysregulation. Psychiatry Research. 49. 257-272.

Prien, R. F. \& Gelengerg, A. J. (1989) Alternatives to lithium for preventtve treatment of bipolar disorder. American Journal of Psychiatry, 146, 840-848.

SCHAFF, M. R., FAWCETT, J. \& ZAJECKA, J. M. (1993) Dtvalproex sodium in the treatment of refractory affective disorders. Journal of Clinical Psychiatry. 54. 380-384.

SHAw, D. M. (1988) Drug alternattves to lithium in manicdepressive disorders. Drugs, 36, 249-255.

SMALl, J. G., KLAPPER, M. H., Mirsten, V., et al (1991) Carbamazepine compared to lithium in the treatment of mania. Archives of General Psychiatry, 48, 915-921.

SUPPES, T., PHIIPS, K. A. \& JUDD, C. R. (1994) Clozapine treatment of nonpsychotic rapid cycling bipolar disorder: a report of three cases. Biological Psychiatry. 36. 338-340.

*David Taylor, Chief Pharmacist, Denise Duncan, Senior Drug Information Pharmacist, The Maudsley Hospital, Denmark Hill, London SE5 $8 A Z$

*Correspondence 